\title{
ЗЕМЕЛЬНО-ПРАВОВЫЕ ПРОБЛЕМЫ РАЗМЕЩЕНИЯ ЛИНЕЙНЫХ И ИНЫХ ЭКОНОМИЧЕСКИ ЗНАЧИМЫХ ОБЪЕКТОВ ГОСУДАРСТВЕННОГО И МЕСТНОГО ЗНАЧЕНИЯ
}

\begin{abstract}
Аннотация: В настоящей статье анализируются правовые конструкиии (изъятие земельного участка, сервитут, договор аренды), посредством которых может быть обеспечен доступ к частным земельным участкам в целях размещения на них линейных и иных экономически значимых объектов государственного и местного значения. Предметом изучения являются нормы российского права, регулирующие отношения, связанные со строительством и реконструкцией названных объектов, а также положения доктринальных исследований по изучаемой теме и правовые позици, отраженные в судебной практике. Исследование осуществлено на базе современных общенаучных методов познания (синтеза, системного анализа), а также специальных научных методов (технико-юридическом анализе, сравнительно-правовом и логическом). Авторы приходят к выводу о том, что ни один из указанных правовых механизмов не может быть безусловно рекомендован лицам, заинтересованным в размещении на частных земельных участках линейных и иных экономически значимых объектов государственного и местного значения, в связи с наличием правовых проблем при их применении. С учетом этого формулируются предложения по совершенствованию действующего законодательства.
\end{abstract}

Ключевые слова: Размещение, договор аренды, сервитут, изъятие земельного участка, объекты местного значения, объекты государственного значения, линейные объекты, строительство, реконструкиия, баланс интересов. Abstract: This article presents analysis of the legal constructs (seizure of land, easement, lease agreement), which would allow access to private land for the purpose of placing linear or other economically significant objects of state and local importance. The subject of this study is the norms of the Russian legislation that regulates the relations pertaining to construction and reconstruction of such objects, as well as the positions of doctrinal research on this topic and legal positions reflected in legal precedent. The authors come to a conclusion that none of the stated legal mechanisms can be unequivocally recommended to persons interested in placement of linear or other economically significant objects on private land due to legal issues associated with their application. Based on this fact, the authors formulate a proposal on improving the current legislation.

Keywords: Placement, Lease agreement, Easement, Seizure of land, Objects of local importance, Objects of state importance, Linear objects, Construction, Reconstruction, Balance of interests.

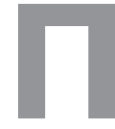

отребность в размещении [1] на территории Российской Федерации большого количества линейных и иных экономически значимых объектов государственного и местного значения (далее - Объекты [2]) обусловлена рядом объективных обстоятельств. В качестве таковых можно назвать существенную протяженность границ России, отдаленность ее наиболее важных административных центров друг от друга, необходимость реализации масштабных инвестиционных (строительных) проектов [3].

Следует отметить, что понятия «объекты федерального значения», «объекты регионального значения», «объекты местного значения» раскрываются в п.п. 18-20 ст. 1 Градостроительного кодекса Российской Федерации [4] (далее - ГрК РФ). С учетом указанных положений можно сделать вывод, что для отнесения объекта к объектам государственного (федерального или регионального) или местного значения, его размещение: а) должно быть необходимо для осуществления полномочий по вопросам, отнесенным к ведению Российской Федерации, субъектов Российской Федерации, органов местного самоуправления;

б) должно оказывать существенное влияние на социально-экономическое развитие Российской Федерации, субъекта или муниципального образования.

Строительство и реконструкция Объектов требует обеспечения доступа лиц, заинтересованных в их размещении, к земельным участкам, которые необходимы для проведения соответствующих работ. Такие земельные участки могут находиться как в публичной, так и в частной собственности. Это обстоятельство влияет на то, посредством каких правовых механизмов может быть обеспечен доступ к требуемым земельным участкам. В настоящей статье предлагаем проанализировать проблемы, связанные с размещением Объектов на частных земельных участках. 
DOI: $10.7256 / 1811-9018.2015 .11 .16678$

При цитировании этой статьи сноска на dоі обязательна

\section{Право и политика 11 (191) • 2015}

Земельный кодекс Российской Федерации [5] (далее - ЗК РФ), подчеркивая значимость Объектов для функционирования экономики государства, допускает для целей их размещения применение исключительной формы ограничения права частной собственности изъятие земельных участков. В качестве альтернативы механизму изъятия земельного участка для целей размещения Объектов могут использоваться также сервитут и договор аренды.

Вместе с тем, нормативно-правовой анализ показывает, что ни одна из указанных правовых конструкций применительно к возможности размещения Объектов не лишена недостатков. В этой связи предлагается последовательно выявить и проанализировать такие недостатки. Подобное исследование видится актуальным, в том числе, в свете новелл правового регулирования изъятия земельных участков для публичных нужд [6] и установления сервитутов [7].

Сначала рассмотрим недостатки конструкции изъятия земельного участка, которые усматриваются при ее использовании для целей размещения Объектов.

Думается, что первым недостатком следует назвать отсутствие в большинстве случаев необходимости собственно изъятия земельного участка.

Механизм изъятия земельного участка, закрепленный в действующем законодательстве, предполагает безвозвратное отчуждение такого участка у его собственника с последующей передачей участка в государственную или муниципальную собственность либо в собственность лицу, заявившему соответствующее ходатайство в порядке ст. 56.4 ЗК РФ. С учетом положений ст. 56.11 ЗК РФ изъятие земельного участка означает прекращение всех правомочий собственника в отношении этого участка и невозможность дальнейшего использования участка его прежним собственником.

Вместе с тем, строительство и реконструкция Объектов зачастую требуют лишь временного использования земельного участка. При этом по окончании технических работ, связанных с размещением Объектов, земельный участок во многих случаях может и далее использоваться в соответствии с его разрешенным использованием. В отдельных же случаях (например, при выполнении регламентных работ в отношении отдельных подземных сооружений или подземных трубопроводов) земельный участок может использоваться собственником в соответствии с его разрешенным использованием и во время проведения этих работ.

Вторым недостатком видится то, что законодатель не предусматривает возможность изъятия для публичных нужд части земельного участка [8].
Вместе с тем для целей размещения Объектов зачастую не требуется использование всего земельного участка, на котором такой объект предполагается к строительству или уже расположен. Так, в определенных случаях для размещения Объектов (например, трубопроводов или линий электропередач) бывает вполне достаточно узкой полосы, составляющей незначительную часть всего земельного участка.

Использование в рассматриваемом случае исключительно механизма изъятия земельных участков, находящихся в частной собственности и необходимых для размещения Объектов, может привести к формированию на балансе собственников таких объектов значительного количества земельных участков, приобретения которых в собственность не требуется. Например, при пересечении трубопроводом линией электропередач большого количества земельных участков, на каждом из которых соответствующий объект занимает небольшую полосу, очевидно, потребуется изъятие всех земельных участков.

В свою очередь, приобретение значительного количества земельных участков в порядке их изъятия у частных собственников может повлечь за собой дополнительные расходы на их содержание. При этом для собственников Объектов изъятые земельные участки становятся непрофильным активом, поскольку фактически будут использоваться только их отдельные части.

В силу действующего законодательства приобретение посредством изъятия у собственника части земельного участка фактически возможно лишь посредством раздела исходного земельного участка. Такой подход требует проведения дополнительных кадастровых работ, что также может повлечь за собой дополнительные финансовые расходы собственников Объектов. Кроме того, такое образование новых участков с их последующим изъятием может привести к вклиниванию, вкрапливанию, изломанности границ, чересполосице, что, в свою очередь, может потребовать обременения изъятых земельных участков сервитутами для обеспечения собственнику прохода от одного принадлежащего ему земельного участка к другому.

Третьим недостатком, препятствующим применению конструкции изъятия земельного участка для указанных случаев являются значительные временные и финансовые затраты, связанные с реализацией этой процедуры.

Процедура изъятия земельного участка, последовательность прохождения которой изложена в гл. VII.1 ЗК РФ, является довольно продолжительной по времени. При этом она обусловлена обязательным участием в ней органов власти, принимающих решения относительно изъятия. 
Так, собственнику или заказчику строительства Объектов необходимо совершить значительное количество различных юридических и фактических действий: предварительно подготовить и направить в уполномоченный орган ходатайство об изъятии земельного участка, установить владельцев земельных участков, пройти процедуру опубликования сообщения о предстоящем изъятии земельного участка, получить согласие уполномоченного органа на его изъятие, определить сумму справедливого возмещения собственнику изымаемого земельного участка или провести работы, связанные с предоставлением ему другого земельного участка взамен изымаемого, определить юридическую судьбу объектов, расположенных на изымаемом земельном участке (в отдельных случаях - сумму компенсации за их изъятие) и т.д.

Указанные выше действия, безусловно, являются разумными и оправданными в ситуациях, когда необходимо принудительное отчуждение у частного собственника принадлежащего ему земельного участка и возникновение права собственности у организации, размещающей объект. Однако совершение некоторых из них (подготовка и направление ходатайства, осуществление публикаций, получение решения уполномоченного органа об изъятии земельного участка) в ситуации, когда необходимо только временное занятие земельного участка, представляется избыточным.

Следует подчеркнуть, что изъятие земельного участка в силу ст. 56.8 ЗК РФ является строго возмездным. При этом полной компенсации собственнику изымаемого земельного участка всегда подлежат: рыночная стоимость изымаемого земельного участка, рыночная стоимость неотделимых улучшений земельного участка, убытки, причиненные изъятием земельных участков, включая убытки, возникающие в связи с невозможностью исполнения собственником земельного участка обязательств перед третьими лицами, в том числе основанных на заключенных с такими лицами договорах, а также упущенная выгода.

Таким образом, процедура изъятия частного земельного участка сопровождается значительными финансовыми затратами заинтересованных лиц. Между тем, собственниками объектов, перечисленных в ст. 49 ЗК РФ, зачастую являются компании с преобладающей долей государственного участия. Следовательно, ограничение для таких компаний возможности возмездного использования чужих земельных участков исключительно принудительным изъятием таких участков повлечет за собой дополнительные финансовые издержки, которые фактически приведут к увеличению государственных расходов на строительство и реконструкцию Объектов.

Увеличение финансовых затрат на строительство и эксплуатацию Объектов может также привести к соответствующему росту тарифов на товары и услуги, реализация которых непосредственно связана с необходимостью строительства и реконструкцией Объектов, что негативно отразится на конечных потребителях таких товаров и услуг (гражданах и организациях).

Далее предлагаем проанализировать недостатки установления сервитута в отношении земельного участка для целей размещения Объектов.

Первый недостаток установления сервитута кроется в том, что в силу п. 1 ст. 274 ГК РФ сервитут может быть установлен для строительства, реконструкции и (или) эксплуатации исключительно линейных объектов. Однако не все Объекты являются по своим признакам линейными [9].

Следовательно, в случае применения правовой конструкции сервитута к регулированию рассматриваемых отношений значительная их часть (а именно та, которая связана с размещением нелинейных объектов) окажется не охваченной таким правовым регулированием. Таким образом, сервитут также не может служить исключительной правовой конструкцией для решения вопроса при размещении объектов.

Вторым недостатком видится то, что согласно тому же п. 1 ст. 274 ЗК РФ установление сервитута предполагает полное отсутствие препятствий в использовании собственником земельного участка своего участка в соответствии с его разрешенным использованием в течение всего срока действия обременения. Буквальное толкование позволяет отметить, что возможность использования собственником земельного участка своего участка ограничиваться никаким образом (даже минимально) не должно.

Вместе с тем специфика строительства и реконструкции Объектов в реальности такова, что на период проведения указанных работ собственник земельного участка может быть лишен возможности использования земельного участка. Такое ограничение правомочий собственника земельного участка формально не согласуется с правовой конструкцией сервитута. В указанном случае правовой конструкцией, которая отвечает требованиям закона, является договор аренды соответствующего земельного участка (или его части).

Думается, что публичный сервитут к урегулированию рассматриваемой ситуации вовсе неприменим в связи со следующим. 
DOI: $10.7256 / 1811-9018.2015 .11 .16678$

При цитировании этой статьи сноска на dоі обязательна

\section{Право и политика $11(191) \cdot 2015$}

Согласно п. 3 статьи 23 ЗК РФ публичный сервитут может быть установлен только в исчерпывающем перечне случаев, среди которых отсутствует такое основание как «для строительства, реконструкции и (или) эксплуатации объектов, указанных в подп. 2 п. 1 ст. 49 ЗК РФ». В силу сказанного публичный сервитут не может быть рассмотрен в качестве правового механизма для обеспечения доступа к земельному участку.

Более того, согласно п. 6 ст. 23 ЗК РФ, если установление публичного сервитута приводит к существенным затруднениям в использовании земельного участка, то его собственник вправе требовать от органа государственной власти или органа местного самоуправления, установивших публичный сервитут, соразмерную плату. Следовательно, установление публичного сервитута в рассматриваемой ситуации может быть сопряжено с дополнительными расходами государственной или муниципальной казны.

Наконец, обозначим недостатки договора аренды земельного участка, заключаемого для целей размещения Объектов.

Перечисленные выше проблемы, возникающие при применении изъятия земельного участка и установления сервитута, потенциально могут быть решены путем заключения с собственником земельного участка договора аренды такого участка для целей размещения Объектов. Так, договор аренды может быть заключен для размещения любого (как линейного, так и нелинейного) объекта, его условия могут быть сопряжены с каким-либо ограничением собственника земельного участка в возможности использования такого участка, этот правовой инструмент является гораздо более оперативным и менее затратным, нежели процедура изъятия земельного участка.

Вместе с тем в настоящее время лица, планирующие размещение линейных и иных наиболее экономически значимых объектов нередко сталкиваются с крайне завышенными требованиями арендодателей (частных собственников земельных участков) при определении размера арендной платы.

В связи с этим, на наш взгляд, следует вспомнить Постановление Президиума ВАС РФ от 11.02.2014 по делу № A19-2903/10-58 [10], в котором сформулирован вывод о том, что условие договора, определяющее предоставление со стороны одного лица, существенно превышающее встречное предоставление или обычную рыночную цену, уплачиваемую в подобных случаях, может свидетельствовать о недобросовестном поведении, являющемся основанием для признания сделки недействительной в соответствии со статьями 10 и
168 ГК РФ. Между тем, судебный способ защиты прав применительно к рассматриваемым правоотношениям, на наш взгляд, не является эффективным, поскольку в связи с признанием договора аренды недействительным арендатор потенциально лишается оснований для использования земельного участка и вынужден искать иные способы оформления прав на земельный участок либо иной земельный участок, что зачастую сопряжено со значительными финансовыми затратами.

Следует отметить, что в настоящее время приняты и действуют федеральные нормативные правовые акты, регулирующие порядок определения предельной платы за предоставление в пользование земельных участков, находящихся в публичной собственности [11], а также соответствующие нормативные акты субъектов Российской Федерации и муниципальных образований. При этом аналогичное правовое регулирование предельных ставок арендной платы за использование земельных участков, находящихся в частной собственности, отсутствует.

Представляется, что возможным вариантом решения указанной проблемы может послужить разумное совершенствование правового института аренды частных земельных участков, направленное на достижение баланса интересов частного собственника земельных участков и лиц, осуществляющих размещение Объектов. В этой связи следует взвесить и рационально оценить возможность установления в федеральном законодательстве пределов арендной платы в отношении находящихся в частной собственности земельных участков, необходимых для размещения Объектов.

Видится, что ориентиром при решении названного вопроса может являться правовая позиция Конституционного суда Российской Федерации, сформулированная им в Постановлении от 25.04.2011 № 6-П [12]. Согласно указанному судебному акту право частной собственности не является абсолютным и может быть ограничено при соблюдении определенных условий:

a) если такие ограничения необходимы для защиты других конституционно значимых ценностей, в том числе частных и публичных прав и законных интересов других лиц;

б) если такие ограничения отвечают требованиям справедливости, разумности, соразмерности;

в) если при этом сохраняются гарантии охраны частной собственности (возмещение при лишении) и гарантии судебной защиты [13].

Кроме того, думается, что поскольку для целей размещения Объектов законодатель допускает изъятие частных земельных участков (т.е. меру исключительно- 
DOI: 10.7256/1811-9018.2015.11.16678

При цитировании этой статьи сноска на dоі обязательна

Юридический практикум

го и бессрочного характера), то ограничение предельных ставок арендной платы (т.е. меру временного характера) за использование тех же земельных участков принципиально не будет противоречить существующему подходу законодателя к ограничению прав частных собственников земельных участков.

В качестве вывода обозначим следующее. В настоящее время ни один из рассмотренных правовых механизмов не может быть рекомендован лицам, заинтересованным в размещении линейных и иных экономически значимых объектов государственного и местного значения, в связи с наличием правовых проблем в их применении. Так, использование конструкции изъятия земельного участка и сервитута видится зачастую нецелесообразным или вовсе невозможным, а заключение договора аренды может быть сопряжено с экономически необоснованными требованиями собственника участка в части размера арендной платы. С учетом этого, наш взгляд, перспективным видится совершенствование правового регулирования арендных отношений путем поиска оптимального баланса интересов сторон при определении размера арендной платы за пользование соответствующими земельными участками.

\section{Сноски:}

[1] В настоящей статье понятие «размещение» предлагаем использовать в его узком значении, предполагающем только «строительство и реконструкцию». Подробнее по этому вопросу см. Письмо Минэкономразвития России от 25.06.2015 № Д23и-3051 // СПС КонсультантПлюс.

[2] На наш взгляд, к таковым следует относить, прежде всего, те объекты, которые прямо перечислены законодателем в п. 2 ст. 49 Земельного кодекса Российской Федерации (далее - ЗК РФ): объекты энергетических систем федерального и регионального значения, объекты использования атомной энергии, объекты обороны страны и безопасности государства, объекты федерального транспорта, объекты связи федерального значения и т.д. Их особая экономическая значимость подчеркивается тем обстоятельством, что законодатель допускает для целей строительства и реконструкции таких объектов изъятие земельных участков (в исключительных случаях).

[3] В качестве актуального примера можно привести строительство газопровода «Сила Сибири». Подробнее об этом см.: Приказ Минпромторга России № 651, Минэнерго России № 172 от 08.04.2014 «Об утверждении Стратегии развития химического и нефтехимического комплекса на период до 2030 года» // СПС КонсультантПлюс.

[4] Градостроительный кодекс Российской Федерации от 29.12.2004 № 190-Ф3 // С3 РФ. 2005. № 1 (часть 1). Ст. 16.

[5] Земельный кодекс Российской Федерации от 25.10.2001 № 136-ФЗ (ред. от 05.10.2015 г.) // С3 РФ. 2001. № 44. Ст. 4147.

[6] По этому вопросу см. подробнее: Болтанова Е.С. Правовое регулирование принудительного отчуждения недвижимого имущества для государственных или муниципальных нужд // Имущественные отношения в Российской Федерации. 2015. № 6. С. 6-15; Майборода В.А. Изъятие земельных участков для публичных нужд // Правовые вопросы недвижимости. 2015. № 1. С. 28-32; Хаустов Д.В. Обзор нового законодательства и судебной практики // Экологическое право. 2015. № 3. С. 40 - 47; и др.

[7] По этому вопросу см. подробнее: Аверьянова Н.Н. Новое законодательство о земельных сервитутах // Право и экономика. 2015. № 2. С. 63-67; и др.

[8] Аналогичный вывод находит отражение, в том числе, в Письме Минэкономразвития РФ от 22.07.2011 № ОГ-Д23-541 // СПС КонсультантПлюс.

[9] При этом употребляемые законодателем в п. 1 ст. 274 ГК РФ слова «а также других нужд собственника недвижимого имущества, которые не могут быть обеспечены без установления сервитута», на наш взгляд, не могут быть распространены на случаи строительства, реконструкции и (или) эксплуатации нелинейных объектов. В противном случае теряет смысл прямое указание в этой же статье на линейные объекты.

[10] См. Постановление Президиума ВАС РФ от 11.02.2014 № 13846/13 по делу № А19-2903/10-58 // СПС КонсультантПлюс.

[11] Основным федеральным актом по указанному вопросу является Постановление Правительства РФ от 16.07.2009 № 582 «Об основных принципах определения арендной платы при аренде земельных участков, находящихся в государственной или муниципальной собственности, и о Правилах определения размера арендной платы, а также порядка, условий и сроков внесения арендной платы за земли, находящиеся в собственности Российской Федерации» // СЗ РФ. 2009. № 30. Ст. 3821 .

[12] См. Постановление Конституционного Суда РФ от 25.04.2011 № 6-П // СПС КонсультантПлюс. Аналогичные выводы находят отражение и в дру- 
DOI: 10.7256/1811-9018.2015.11.16678

При цитировании этой статьи сноска на доі обязательна

\section{Право и политика $11(191) \cdot 2015$}

гих судебных актах Конституционного суда РФ (Постановления от 20 мая 1997 года № 8-П, от 16 июля 2008 года № 9-П и от 31 января 2011 года № 1-П).

[13] Любопытно в этой связи заметить, что Европейским Судом по правам человека также выработаны ряд условий, при соблюдении которых допустимо ограничение права собственности. К таким условиям ЕСПЧ отнес: во-первых, законность: соответствие национальному законодательству и практике, принцип правовой определенности (см., например, Постановление ЕСПЧ по делу «Бывший Король Греции и другие против Греции» от 23.11.2000); во-вторых, общественный интерес (см., например, Постановление ЕСПЧ по делу «Папахелас против Греции»от 25.03.1999); в-третьих, требование справедливого баланса интересов сторон (см., например, Постановление ЕСПЧ по делу «ПрессосКомпаниаНавьера С.А.» и другие против Бельгии» от 20.11.1995).

\section{Библиография:}

1. Аверьянова Н.Н. Новое законодательство о земельных сервитутах // Право и экономика. 2015. № С. 63-67.

2. Болтанова Е.С. Правовое регулирование принудительного отчуждения недвижимого имущества для государственных или муниципальных нужд // Имущественные отношения в Российской Федерации. 2015. № 6. С. 6-15.

3. Майборода В.А. Изъятие земельных участков для публичных нужд // Правовые вопросы недвижимости. 2015. № 1. С. 28-32.

4. Хаустов Д.В. Обзор нового законодательства и судебной практики // Экологическое право. 2015. № 3. С. 40 - 47.

\section{References (transliterated):}

1. Aver'yanova N.N. Novoe zakonodatel'stvo o zemel'nykh servitutakh // Pravo i ekonomika. 2015. № S. 63-67.

2. Boltanova E.S. Pravovoe regulirovanie prinuditel'nogo otchuzhdeniya nedvizhimogo imushchestva dlya gosudarstvennykh ili munitsipal'nykh nuzhd // Imushchestvennye otnosheniya v Rossiiskoi Federatsii. 2015. № 6. S. 6-15.

3. Maiboroda V.A. Iz”'yatie zemel'nykh uchastkov dlya publichnykh nuzhd // Pravovye voprosy nedvizhimosti. 2015. № 1. S. 28-32.

4. Khaustov D.V. Obzor novogo zakonodatel'stva i sudebnoi praktiki // Ekologicheskoe pravo. 2015. № 3. S. 40 - 47. 